\title{
A política é a arma do negócio: o papel dos EUA e das Corporations na construção da ditadura chilena
}

\author{
Politics is the weapon of the business: \\ the role of USA government and the corporations \\ in Chile's dictatorship \\ La política es el la arma del negocio: \\ el papel de los Estados Unidos y de las Corporations \\ en la construcción de la dictadura chilena
}

Tatiana Poggi*

\begin{abstract}
Resumo: Este artigo busca abordar as relações entre o governo EUA e grandes conglomerados privados norte-americanos e chilenos, revelando seu papel na derrubada do governo Allende e na construção da ditadura no Chile. Primeiramente, destacaremos as relações entre o poder público e os interesses privados, influenciando políticas públicas, comumente expostas como de interesse nacional, público, de todos. Então, procuraremos entender o processo de construção da ditadura chilena a partir de uma abordagem global, relacionado às dinâmicas do capitalismo contemporâneo, marcado pela transnacionalização da produção, da política, de ideologias e mentalidades.

Palavras-chave: Chile; ditadura militar; EUA; empresários

Abstract: This paper addresses the relations between the US government and northAmerican and Chilean conglomerates, unveiling their role overthrowing Allende's government and sustaining the dictatorship in Chile. We start by presenting a theoretical discussion highlighting the relationship between public power and private interest, which influences policymaking. Second, an analysis of the social construction of the dictatorship in Chile is presented, connected to the contemporary dynamics of capitalism, characterized by the transnationalization of production, politics, ideologies and mentalities.
\end{abstract}

Keywords: Chile; military dictatorship; USA; business

\footnotetext{
* Doutora. Professora de História Contemporânea da Universidade Federal Fluminense (UFF). $<$ tatiana.poggi@gmail.com> < dados biográficos/biographic data>
} 
Resumen: Este artículo busca abordar las relaciones entre el gobierno de los Estados Unidos y grandes conglomerados privados norteamericanos y chilenos, revelando su papel en la caída del gobierno Allende y en la construcción de la dictadura en Chile. En primer lugar, destacamos las relaciones entre el interés público y los intereses privados y de que manera influyen en las políticas públicas, comúnmente expuestas como de interés nacionales, público, de todos. Finalmente, buscamos entender el proceso de construcción de la dictadura chilena desde un enfoque global, en relación con las dinámicas del capitalismo contemporáneo, marcado por la transnacionalización de la producción, de la política, de ideologías y mentalidades.

Palabras clave: Chile; dictadura militar; EE.UU.; empresarios

\section{Os espaços de atuação do capital nacional e transnacional}

Em A internacional capitalista: estratégias e táticas do empresariado transnacional 1918-1986, René Dreifuss (1986) aborda as diversas formas da classe dominante fazer política e se relacionar com o poder, desde as mais explícitas, como o financiamento de campanha de candidatos, até as mais sofisticas e profundas, como a articulação política suprapartidária em organizações privadas transnacionais. Seu esforço está em desvendar como os setores dominantes se organizam e atuam na arena política, explicitando as íntimas relações entre poder econômico e poder político, de modo a que possamos entender como "uma classe traduz suas capacidades estruturais (o predomínio econômico na esfera da produção, sua formação intelectual e seu acervo cultural, suas ligações pessoais e vínculos familiares ampliados) em capacidades político-organizacionais" (DREYFUSS, 1986, p. 21).

Ancorado no pensamento político de Gramsci, Dreifuss dedicase nesse livro especialmente ao estudo dos organismos privados transnacionais, criados pela classe dominante dos países centrais, entendendo-os como sustentáculos ideológico-políticos da dominação. Tais organismos consistiriam em institutos de pesquisa, fundações, clubes de empresários e agências de planejamento e consultoria, visando conquistar, salvaguardar e consolidar sua posição, seus privilégios na sociedade e no campo internacional. $\mathrm{O}$ investimento em espaços políticos privados dessa natureza, aliado ao controle dos meios de produção, assegurariam a consecução dos objetivos e interesses dos grupos dominantes, expressos através da implementação de políticas públicas e do uso dos aparatos de força do Estado em benefício desse setor. Tal processo de direção política e ideológica, conjugado à coerção 
econômica e à autoridade sobre a violência legítima, foi nomeado por Gramsci como construção de hegemonia.

A relação de hegemonia é um processo em permanente construção, uma relação social complexa e dinâmica, convivendo o tempo todo com resistências e antagonismos de variadas dimensões. Nesse sentido, os espaços ou os canais através dos quais a hegemonia ou a dominação são construídos tornam-se espaços de conflito, espaços de luta. As instituições públicas, ou seja, a ossatura material do Estado, os aparelhos de hegemonia, os partidos e a política, de uma forma geral, configuram espaços de disputa por excelência.

Os organismos privados contribuem por tornar a ação política mais eficaz, propiciando os instrumentos (informação, análise, articulação e formulação de diretrizes) para uma melhor organização e operacionalização dos anseios de uma classe na forma de um projeto de sociedade. Não por acaso, boa parte desses organismos se constituem em centros de pesquisa, de estudos estratégicos, fundações, clubes e associações que financiam e estimulam pesquisas. O poder de uma classe é igualmente exercido através de sua ação política, implementada e planejada estrategicamente nesses espaços privados de hegemonia. Como podemos perceber, projetos, campanha e a política de uma forma mais abrangente ultrapassam a organização político-partidária, incluindo também os organismos privados.

Pelo lado do Estado, poder-se-ia, então, pensar que este estaria refém dos dítames do empresariado e seus organizamos privados. Correntes heterodoxas do marxismo, em especial no âmbito do pensamento gramsciano, apostam na dialética, construindo fortes críticas ao mecanicismo e às abordagens reflexivas da relação Estado-sociedade. O Estado, então, é entendido dentro de uma perspectiva relacional, expressando a correlação de forças de um dado contexto histórico. Projetos, campanhas, legislações e as políticas públicas de forma geral são construções dos homens; homens com interesses, opiniões e gostos, que se articulam politicamente a atuam no Estado diretamente ou por meio de outros homens que representam seus interesses. O Estado não é uma esfera neutra, que atua objetivamente; também não consiste num espaço vazio a ser tomado. O Estado é uma construção social e por isso expressa as contradições dos homens e da sociedade; expressa conflitos, desigualdades e resistências (GRAMSCI, 2002, p. 11-111; POULANTZAS, 1985, p. 141-187).

De acordo com James O'Connor, o Estado no capitalismo, através das ações políticas articuladas pelos homens, desempenha duas funções 
básicas: acumulação e legitimação. O Estado tem de tentar manter ou criar as condições necessárias para uma exponencial acumulação de capital, ao mesmo tempo em que deve trabalhar para manter ou criar condições que minimizem conflitos sociais. O emprego aberto da força para auxiliar a acumulação de capital põe em xeque a legitimidade do governo vigente, abalando sua base de apoio social. Entretanto, ignorar assistência ao processo de acumulação põe em risco a fonte de seu próprio poder, bem como a capacidade de produção de excedentes econômicos e, consequentemente, os impostos arrecadados desse mesmo excedente. "O Estado deve envolver-se no processo de acumulação, porém tem de fazê-lo mistificando sua política, denominando-a algo que não é, ou tem de ocultá-la (por exemplo, transformando temas políticos em temas administrativos)" (O`CONNOR, 1977, p. 19).

Assim, O'Connor destaca primeiramente a estreita relação entre poder público e privado e, finalmente, o fato de todas as despesas e políticas públicas terem um duplo caráter: carregar esse duplo compromisso com a acumulação e com a legitimação. O duplo compromisso, explica também muito sobre a forma como as ações políticas são traduzidas, expressas publicamente de forma burocratizada, institucionalizada - como se burocracias, instituições e políticas públicas não fossem também construções sociais - ou mesmo naturalizada.

Segundo Dreifuss, os primeiros grupos privados transnacionais, voltados para a construção de hegemonia surgiram no início do XX. Os Round Table Groups foram concebidos como um esforço de montagem de uma rede de organizações britânicas e norte-americanas, sob a liderança dos empresários Cecil Rhodes e William Stead, além do apoio de J. P. Morgan. Mesmo ganhando destaque durante a Primeira Guerra Mundial, ao participar da formulação dos projetos de guerra do império britânico, os Round Table Groups não tiveram vida longa, durando apenas 10 anos.

O Council on Foreign Relations (CFR), apesar de não ser um organismo propriamente transnacional, primando pela expansão dos interesses do capital norte-americano, teve mais sucesso em construir hegemonia a longo prazo. Fundado em 1918, o CFR foi o primeiro grande organismo privado a ser bem sucedido na interação orgânica entre os mundos dos negócios e da finança, da política, da imprensa e das universidades. O organismo tinha como objetivo analisar, formular e avaliar diretrizes públicas e privadas, indispensáveis para sustentar a projeção do capitalismo norte-americano. Seu corpo de membros reunia industriais, banqueiros, militares, intelectuais, burocratas, 
grandes figuras da mídia, empenhados em combater as propostas intervencionistas e distributivas do New Deal, bem como a abordagem isolacionista da política externa norte-americana (DOMHOFF, 1971, p. 89-90; WOLFE, 1981, p. 37).

Contudo, apenas a partir da década de 1940, através do War and Peace Studies, o CFR encontraria mais receptividade e espaço para implementar seus projetos. Os estudos buscavam conjugar os interesses industriais e financeiros com as demandas das grandes lideranças civis e militares em tempo de guerra. Entretanto, mais até que os propósitos de guerra, os estudos diziam respeito a uma nova ordem política e econômica, construída após a guerra e adequada às necessidades do empresariado vinculado ao CFR.

A experiência e o êxito do CFR estimularam a fundação, em 1942, do primeiro organismo privado transnacional nos EUA, o Committee for Economic Development (CED). Segundo Karl Schriftgiesser, o CED consistiria numa combinação de empresários e acadêmicos de grandes universidades, num esforço conjunto de pesquisa econômica e policymaking, "um experimento intelectual inigualável na comunidade de negócios da América - uma fusão das melhores mentes das corporações mais bem-sucedidas e das melhores universidades, neste esforço comum" (SCHRIFTGIESSER, 1960, p. vi-vii).

Outro diferencial trazido pelo CED, além do já mencionado caráter transnacional e, portanto, não restrito apenas ao avanço dos interesses do capital norte-americano, foi tentar atrair pra sua base de apoio não apenas os sujeitos mais diretamente beneficiados com seus projetos, mas também outros segmentos da sociedade por meio do investimento em estratégias ideológicas e propagandísticas. Daí a preocupação constante em estabelecer conexões com outros organismos privados, think tanks ao redor mundo; em fomentar a organização política do empresariado; em popularizar e expandir seus ideais dentre os setores dominados. Tais laços solidificam a rede de suporte aos interesses do capital internacional. Este esforço de projetar internacionalmente seus interesses e anseios particulares, de classe, como interesse geral fez do CED um autêntico partido no sentido gramsciano ${ }^{1}$.

\footnotetext{
${ }^{1}$ Além do CED podemos citar outros importantes organismos privados transnacionais e think tanks de âmbito nacional, surgidos posteriormente. Em seu corpo de diretores, encontramos boa parte dos membros do CED e do CFR: Business Council, Trilateral Comission, Business Roundtable, Action Committee for Europe, Rand Corporation, Brookings Intitution, Heritage Foundation, Hudson Institute, Institute for Defense Analysis, Century Association, Rockefeller Commission, Foreign Policy Association.
} 
A partir as décadas de 1950 e 1960, empresários dos países centrais voltaram sua atenção às políticas de desenvolvimento da periferia, investindo fortemente na transnacionalização de suas unidades produtivas - multinacionais - e no "apoio político e econômico aos governos e às elites modernizante-conservadoras, consideradas "pró-ocidentais", que favoreciam a transnacionalização dos mercados, das estruturas produtivas e dos circuitos financeiros" (DREIFUSS, 1986, p. 106).

Novamente observamos a ação contundente do CED assessorando as administrações Eisenhowher, Kennedy e Johnson no sentido da necessidade de modernização da periferia, em especial da América Latina; estreitando laços e financiando entidades latino-americanas de natureza semelhante ${ }^{2}$; desenvolvendo projetos conjuntos no sentido da globalização econômica e da contenção de tendências políticas perigosas de cunho coletivista, "esquerdista".

Para além do CED, outros organismos desempenharam um papel no tocante às relações com a América Latina, explicitando o poder de influência do empresariado na condução de políticas públicas nos EUA e na América Latina. São eles: Conselho Interamericano de Comércio e Produção (Cicyp), United States Inter-American Council, Business Group for Latin America, Latin American Information Committee, Council for Latin America, Council of the Americas, Americas Society. Esses organismos alimentaram grandes programas públicos de desenvolvimento como a "Aliança para o Progresso", promovido pelo governo Kennedy (DREIFUSS, 1986, p. 111)3.

Os grupos privados latino-americanos, por sua vez, buscavam construir consenso no interior de suas próprias sociedades, estar à frente da direção intelectual e moral para por em prática projetos alinhados com a modernização conservadora. Para isso, fazia-se necessário

\footnotetext{
${ }^{2}$ Brasil: Instituto de Pesquisas e Estudos Sociais (Ipes), Sociedade de Estudos Interamericanos. Chile: Instituto Privado de Investigaciones Económico-Sociales, Foro de la Liberdad de Trabajo. Argentina: Centro de Estudios sobre la Liberdad, Foro de la Libre empresa, Acción Coordinadora de lãs Instituiciones Empresariales Libres. Peru: Instituto de Acción Social, Centro de Orientación Económico-Social, Acción para el Desarollo. México: Instituto de Investigaciones Sociales y Económicas (Ilse), Centro de Estudios Monetários Latino-Americanos. Venezuela: Instituto Venezuelano de Analisis Económico-Social (Ivaes), Unidade de Acción Vallecaucana (UAV). Colombia: Centro de Estudio y Acción Social, Fundación para Estudios sobre la Liberdad.

3 "O comitê de empresas para a implementação da Aliança para o Progresso era composto de diretores de grandes corporações com interesses vultosos na América Latina, entre elas, a Grace Line; Caterpillar Tractor Co.; Godfrey L Cabot; The Anaconda Co.; Standard Oil; Marshal Erdman; Koppers Co.; Sears; Roebuck \& Co.; Ford Motor Co.; Willys Motors; Aluminium Co.; International Minerals \& Chemical Corp.; General Foods Corp.; Food Machinery; Chace Manhattan Bank; American Machine; The First Boston Corp; Pan American; e First National City Bank." (DREIFUSS, 1986, p. 111).
} 
investir na formulação de um projeto de sociedade e de um conjunto de políticas públicas que viessem expressar os anseios e visões de mundo do empresariado regional, bem como na desarticulação dos grupos subordinados e oposicionistas, através de estratégias de convencimento e/ou mecanismos de coerção pública e privada.

\section{As formas de organização e articulação política do empresariado chileno}

No Chile, em particular, observamos essa forma de organização política em grupos como a Sociedad de Fomento Fabril (SOFOFA), a Cia de Estudos Sociais Econômicos e Culturais (Codesec), Foro de la Liberdad de Trabajo e Instituto Privado de Investigaciones Economica y Sociales (IPIES). Temos aqui algumas entidades atuando exclusivamente na produção de conhecimento e de um discurso numa dada direção. As pesquisas produzidas por essas associações visavam organizar intelectualmente um projeto de sociedade, um modo de vida que viesse a atender diretamente os interesses do empresariado chileno e transnacional, pensando estratégias políticas que concretizassem esse ideal. Mais que isso, visavam convencer parcelas mais amplas da sociedade de que seus ideais, seu sonho de mundo era também o sonho a ser perseguido pelos setores populares chilenos, em resumo, que todos se beneficiariam com a implementação do projeto do empresariado.

Já a SOFOFA, outra entidade de destaque na defesa dos interesses do empresariado, se configura como clássica organização patronal similar a Sociedad Nacional de Agricultura, cumprindo uma função organizativa de classe, na promoção e defesa dos interesses de um determinado setor, a dizer o setor industrial chileno.

A SOFOFA foi fundada em 1883 com o propósito de fomentar o investimento em atividades manufatureiras, promover o desenvolvimento industrial e capacitação de mão-de-obra, estimulando a iniciativa privada e o livre mercado. Tais objetivos, bem como o uso da política como canal para realização de seus anseios aparecem de forma bem explícita na página eletrônica da associação.

SOFOFA promueve el desarrollo industrial y el crecimiento económico del país, impulsando y proponiendo políticas públicas que fomenten la inversión, el emprendimiento, la capacitación permanente de los recursos humanos y la generación de empleos. 
Junto con ello, estimula la iniciativa privada, el libre mercado, y la apertura al comercio exterior ${ }^{4}$.

Ao longo deste tempo, a SOFOFA esteve à frente de projetos de promoção do progresso industrial como a Exposição Nacional de 1884; produziu estatísticas nacionais sobre atividade industrial no Chile, publicando-as em boletins regulares; assentou as bases do Decreto-lei sobre a propriedade industrial de 1925; participou das discussões de acordos comerciais estudadas pelo Ministério das Relações Exteriores; e ainda promoveu iniciativas educacionais como a Escuela Profesional de Niñas de Santiago (1887), a Escuela Nocturna de Dibujo de Valparaíso (1894) e a Escuela Práctica de Obreros Electricistas y de Manejo de Motores $(1898)^{5}$.

Hoje, agrupa um conjunto de aproximadamente 2500 empresas nacionais e transnacionais, 38 associações setoriais e 8 gremios empresariais regionais, representando $100 \%$ da atividade industrial do Chile. Importantes empresas da época de fundação como Compañía de Consumidores de Gas, Farmoquímica del Pacífico, Sociedad Industrial Kunstmann e Compañía Sudamericana de Vapores, tornaram-se gigantes do mercado; a SOFOFA cresceu, incorporando novas empresas chilenas e, com o tempo, também alguns ícones do capital transnacional.

Tal direcionamento no desenvolvimento da SOFOFA pode ser observado ao analisarmos a composição dos quadros componentes do comitê executivo e dos conselhos consultivos da entidade. A primeira instância ainda permanece sob o controle do capital chileno. Compõem o comitê executivo: Molymet, Viñedos Emiliana S.A., COPSA, ASIMET, Camport, ASIVA, Enaex S.A., Celulosa Arauco y Constitución S.A., Manufacturas Interamericanas. Já o conselho consultivo é um pouco mais plural, incluindo renomadas multinacionais do Brasil, Espanha, Franca e Suíça ${ }^{6}$.

\footnotetext{
${ }^{4}$ Página eletrônica SOFOFA. Qué es SOFOFA? Disponível em: <http://web.sofofa.cl/corporativa/ quienes-somos/¿que-es-sofofa/>. [Acesso em: maio 2014].

${ }^{5}$ Página eletrônica SOFOFA. Historia SOFOFA. Disponível em: $<$ http://web.sofofa.cl/corporativa/ quienes-somos/historia-sofofa-industria-pionera/>. [Acesso em: maio 2014].

${ }^{6}$ Conselho Consultivo: Fabricas Arteaga S.A., Hilados y Tejidos Garib S.A., Caucho Nova Ltda., Enlozados Cóndor S.A., Enaex S.A., Alimentos Marinos S.A., Inpol Ltda, Metalpar S.A., J. Riveros S. A.I.C., Compañia de Inversiones Valle Alegre, Saieg y Cía Ltda., Forus S.A., Pesquera Iquique Guanaye S.A., Enersis S.A., Galva Ocho Ltda., Indura S.A., SQM S.A., Lan Airlines S.A., Celulosa Arauco y Constitución S.A., Corpora S.A., Iansa S.A., Carozzi S.A., Quiñenco S.A., CGE, Empresas CMPC S.A., Molinera e Industrial de Azapa S.A, Cencosud, Forus S.A., DyS, Asociación Chilena de Seguridad, CTI S.A., Lipigas S.A., SONDA S.A., Empresas COPEC S.A., Morgan Impresores S.A., Compañia Electro Metalúrgica S.A., Compañia General de Electricidad S.A., Molymet, Cía. Sudamericana de Vapores, AGROSUPER, Cemento Polpaico,
} 
A SOFOFA configura um exemplo de um organismo privado, originalmente atuando em âmbito nacional, que se internacionaliza, ou seja, passa a representar e expressar os interesses do capital nacional e transnacional concomitantemente, sem que esses sejam necessariamente conflitantes.

Trata-se aqui de entender o processo de derrubada governo Allende e construção da ditadura chilena como um projeto de classe, muito mais do que derivado de condicionantes puramente externos ou internos. Defendo, antes de tudo, que os interesses são de classe, do empresariado, e esses atravessam fronteiras.

É certo que há conflitos, divergências e interesses particulares entre setores do empresariado, entre empresas nacionais e estrangeiras. Todavia, a experiência recente da SOFOFA revela o fortalecimento da tendência à internacionalização do capital e, analogamente, o crescimento de organismos privados transnacionais dedicados à defesa dos interesses do capital, independente de sua origem ${ }^{7}$. Além disso, em tempo de crise de legitimidade, de ataque aos interesses da classe dominante e de falta de estabilidade política, as desavenças intraclasse se amenizam, ainda que estrategicamente, para que se promovam ações conjuntas.

É segundo essa perspectiva que entendemos o papel dos EUA no golpe e na manutenção da ditadura chilena. Esses processos não devem em absoluto ser vistos como derivados de forças externas, no caso, dos interesses norte-americanos na região. Uma análise nessa direção só viria a corroborar o mecanicismo e as abordagens reflexivas, criticadas há pouco. Acredito que a participação norte-americana deva ser explorada e investigada em conjunto com as estratégias do empresariado chileno para reaver seu lugar de direção política, cultural e moral da sociedade; como um projeto de classe, um projeto social que se expressa numa proposta política (FONTANA, 1998, p. 9-10), atendendo aos interesses do empresariado chileno e de parte do empresariado norte-americano.

Viñedos Emiliana S.A., VULCO S.A., CMPC MADERAS S.A., IPAL S.A., MELÓN S.A., Empresas El Mercurio S.A.P., CAP S.A., Emel S.A., Watt's Alimentos, Malterias Unidas S.A., AES GENER S.A., GTD Teleductos, B.O. Packaging, Veteroquímica, NCR, SODEXO CHILE, Gerdau Aza S. A., Teléfonica Chile S.A., Citroen Chile S. A. C, Nestlé Chile. Página eletrônica SOFOFA. Historia SOFOFA. Disponível em: <http://web.sofofa.cl/corporativa/quienes-somos/estructuracorporativa/>. [Acesso em: maio 2014].

${ }^{7}$ Podemos citar alguns outros organismos transnacionais que atuam mundialmente nesse sentido como a Sociedade de Mont Pelerin, a Comissão Trilateral, RAND Corporation. 


\section{O tempero yankee no caldeirão político do Chile}

A história da ditadura chilena se mistura com a história das empresas no Chile, bem como com a história das multinacionais na economia chilena e das suas relações com o governo chileno e norteamericano. Para entender o papel desempenhado pelo empresariado transnacional, bem como as relações entre Chile-EUA e o envolvimento da CIA durante o período é necessário voltarmos um pouco no tempo, uma vez que a construção do regime ditatorial está intimamente ligada à derrubada do governo democrático popular de Salvador Allende.

As relações entre Chile e EUA tornaram-se mais tensas entre os anos 1960 e 1970 em virtude da maior articulação dos partidos de esquerda e da conquista de seus candidatos de espaços no parlamento e assumindo cargos ministeriais. As tensões se tornam mais evidentes durante a eleição de 1964, disputada por Eduardo Frei e Salvador Allende. Frei, o candidato democrata-cristão, vence as eleições, apoiado e financiado pelo governo norte-americano.

Documentos disponibilizados pela Intelligence Community em setembro de 2000 revelaram a profundidade e natureza das atividades e intervenções dos EUA, em especial da CIA, no Chile entre os anos 1960 e 1970 (CIA Activities in Chile, 2000). O objetivo das primeiras intervenções, até Allende assumir a presidência, era desacreditar lideranças políticas inclinadas ao marxismo ou qualquer proposta reformista de cunho coletivista, em especial Allende, e fortalecer e encorajar a oposição civil e militar. Sob a direção direta da Casa Branca e de Comitês de Coordenação de Política Interagencial, foram, então, elaboradas uma série de operações clandestinas a serem executadas pela CIA, que incluíam esforço propagandístico, apoio financeiro a grandes corporações de mídia locais de oposição a Allende e outros líderes favoráveis à projetos populares, além de apoio político e financeiro à partidos e candidatos afinados com os interesses norte-americanos.

Através do projeto 5412 Panel Special Group a CIA direcionou recursos financeiros constantes ao Partido Democrata Cristão em apoio ao candidato Eduardo Frei; fomentou propaganda de oposição a Allende por meio de um programa de ação política e propaganda direcionada, além do apoio a grupos civis; fez um pagamento em suporte à Frente Democrática; providenciou assistência clandestina ao Partido Radical (CIA Activities in Chile, 2000).

As investidas da CIA continuaram, mesmo Allende sendo derrotado nas eleições. Entre 1967 e 1969, como parte das ações políticas de 
propaganda, a CIA (40 Committee) autorizou verbas significativas para estações de rádio e jornais de grande circulação, bem como um workshop sobre estratégias de propaganda política. Nas eleições de 1969 para o Congresso, a agência (303 Committee) apoiou candidatos moderados (CIA Activities in Chile, 2000).

O clima ficou mais tenso à época da formação do bloco democráticopopular conhecido como UP, cimentando a aliança entre o Partidos Socialista, Partido Comunista, Partido Social-democrata e MAPU (Movimiento de Acción Popular Unitário). A vitória de Allende nas eleições de 1970 mudou o caráter das investidas dos EUA no Chile. O memorando da reunião do 40 Committee, de 9 de setembro de 1970, dias após a vitória de Allende, evidencia a articulação do golpe. Os membros do Comitê mostravam-se descreditados diante cenário não penas da vitória de Allende, mas da dificuldade de articulação da oposição e de uma ação do Congresso.

[Broe] apontou que Frei é uma peça essencial para o sucesso de qualquer ação, do congresso ou militar, para frustrar a tomada de poder por Allende e que o embaixador Korry está pessimista quanto à perspectiva de Frei poder fazer algo além de lamentar a vitória eleitoral de Allende. (...) Sr. Helms, notando que uma ação do Congresso contra Allende era pouco provável, fez uma observação pessoal que, uma vez que Allende assumisse o poder, é previsível que a oposição de desintegre e entre em colapso rapidamente. Ele mostrou-se preocupado que Allende neutralizasse os militares e a polícia, não havendo mais formas efetivas de articular oposição a ele. Sem defender abertamente um golpe, ele pontuou que um golpe militar contra Allende teria poucas chances de sucesso a não ser que empreendido logo (Minutes of the 40 Committee Meeting, 1970).

A CIA, então, pôs em prática um projeto em duas etapas para impedir que o presidente assumisse o cargo. Segundo o relatório do Church Committee, o projeto havia sido aprovado diretamente pelo presidente Nixon e seu secretário de defesa Henry Kissinger, em reunião com o diretor da CIA Richard Helms e o procurador geral John Mitchell em 15 de setembro de 1970. A primeira fase, Track 1, consistiria em uma estratégia constitucional, tentando influenciar o governo chileno a não reconhecer a vitória de Allende, pois não teria vencido a disputa por maioria absoluta. Não tendo sucesso nessa investida, passou-se à segunda fase, Track 2, que previa instigar um golpe de Estado de forma a impedir a ascensão de Allende a presidência. Para por em prática o 
golpe, a CIA trabalhou conjuntamente com três grupos, articulando uma conspiração que envolvia o sequestro do comandante Rene Schneider. A CIA forneceu armamentos como gás lacrimogêneo, metralhadoras e munição aos grupos. No correr dos acontecimentos, o golpe fracassou, mas levou à morte do comandante Schneider, evento do qual a CIA não se responsabiliza, afirmando que a intenção não era matá-lo ( $C I A$ Activities in Chile, 2000).

Além da articulação de um golpe, Nixon e Kissinger exigiram ainda que se colocassem práticas medidas para "esganar a economia" chilena (make economy scream) (CIA Activities in Chile, 2000). Enquanto o golpe resultou em fracasso, a coerção econômica e a continuidade das investidas em propaganda oposicionista foram certamente mais frutíferas. Como veremos adiante, as pressões econômicas revelam as estreitas relações entre governo norte-americano e os grandes conglomerados transnacionais e os impactos desses interesses na sociedade chilena.

A política econômica do presidente Allende assumira um forte tom reformista e nacionalista, prezando por políticas voltadas para a ampla redistribuição de riqueza, nacionalização da exploração dos recursos naturais e de serviços essenciais. Tais medidas ameaçavam diretamente os interesses de grandes companhias nacionais e transnacionais que atuavam nos ramos da mineração, telecomunicações, transporte, etc.

Um programa de reformas nessa direção teria de enfrentar forte oposição. Em resistência às reformas reagiram os empresários, articulando-se com os setores médios e parte da classe trabalhadora e organizando manifestações, protestos e paralisações em todo o país. Segundo Aggio, "a crise de outubro representou a ofensiva mais incisiva e geral da oposição desde o início do governo Allende" (AGGIO, 1993, p.137), revelando o alto grau de mobilização e coordenação da oposição, dirigida pelas organizações patronais. Estavam à frente do processo de articulação política da oposição alguns dos aparelhos privados mais fortes do empresariado chileno, como a Confederação da Produção e do Comércio e a Frente Nacional da Atividade Privada. Essas duas entidades assumiram a direção na articulação das críticas e demandas exigidas por um conjunto de associações comerciais, industriais, da produção agrícola, construção civil, transportes, além de técnicos e profissionais de nível médio (GARRETÓN; MOULIAN, 1983, p. 101).

Outubro de 1972 vivenciou uma série de manifestações, paralisações e greves. Protestos inicialmente localizados, fenômenos regionais, limitados a setores particulares da economia e com reivindicações corporativas ganharam rapidamente dimensão nacional. 
Esse resultado foi possível graças à atuação político-organizativa dos aparelhos privados do empresariado, que trabalharam na superação dos interesses corporativos, particulares de cada ramo do empresariado, e geradores disputas internas, em favor de um projeto comum, agregador dos interesses de classe. Além disso, esses organismos tiveram êxito ainda na conquista de apoio político para além da classe dominante, convencendo parte da classe trabalhadora, em especial os setores médios (AGGIO, 1993, p. 137).

A reação das companhias estrangeiras às iniciativas de Allende veio justamente no sentido de ameaçar a estabilidade do governo com um possível colapso econômico. Grupos como o gigante das telecomunicações IT\&T, as mineradoras Anaconda Copper e Kennecott, a farmacêutica Pfizer Chemical, Purina e Bank of America organizaramse no Ad-Hoc Committee on Chile, sediado em Washington D.C., visando combater a política de nacionalização do governo Allende. O Comitê funcionava como um canal, através do qual as empresas procuravam influenciar a política externa dos EUA em relação ao Chile, fazendo lobby a favor de seus interesses (KLEIN, 2008). Audiências do Senado norte-americano de 1973 revelam que IT\&T recomendou a Kissinger que suspendesse todos os tipos de ajuda econômica ao Chile, além de sugerir ao governo Nixon um plano de golpe preparado pelos analistas da empresa (KLEIN, 2008, p. 65).

As relações com o poder público, contudo, são muito mais profundas e remontam ao início dos anos 1960. No bojo da Guerra Fria e de iniciativas como a "Aliança para o Progresso", grandes corporações fundaram, sob o aval do presidente Kennedy, um organismo privado de nome Business Group for Latin America. No grupo estavam organizadas gigantes empresariais como IT\&T e Anaconda Copper, com investimentos diretos no Chile, além de Standard Oil, United Fruit, U.S. Steel, Ford Motors, E.I. Dupont e Pepsico. Seu objetivo era discutir com integrantes da administração Kennedy diretrizes governamentais para a América Latina, tendo em vista os "problemas políticos" da região (DREIFUSS, 1986, p. 111).

Documentos da CIA revelam que empresários norte-americanos com negócios no Chile procuraram agentes oferecendo fundos para ajudar no combate ao "perigo vermelho" e financiar candidatos conservadores. Nessas iniciativas, a $I T \& T$ mostrou-se como ponta de lança, sendo um de seus diretores, John McCone, um ex-diretor da CIA até 1964. McCone serviu de "ponte" entre a empresa e a CIA, organizando mais de 40 reuniões entre executivos da IT\&T e agentes 
da CIA (KORNBLUH, 2003; WOODIWISS, 2007, p. 175). Temos hoje uma quantidade significativa de registros, documentos e livros que atestam a participação direta da $I T \& T$ na construção e manutenção da ditadura chilena.

Fundada na década de 1920 como uma empresa de telefonia, a IT\&T rapidamente se diversificou, adquirindo uma vasta gama de empresas como distribuidoras de alimentos, locadoras de automóveis, empresas de mídia e seguros. Nos anos 1960, a IT\&T tornara-se um dos maiores conglomerados dos EUA, detendo um total de 350 companhias. Das inúmeras aquisições e fusões feitas ao longo da história da empresa, a compra da Hartford Fire Insurance, maior seguradora dos EUA, colocou a $I T \& T$ numa posição complicada frente à legislação antitruste. E em 1969, um comitê da Câmara dos Deputados preparou um estudo minucioso sobre os seis maiores conglomerados nos EUA, convocandoos para depor. Esse foi o primeiro capítulo de uma longa história de pressões da $I T \& T$ sobre o governo Nixon, com vistas abrandar os efeitos da legislação antitruste e influenciar a política externa no tocante ao Chile (SAMPSON, 1973, p. 13, 146, 152, 159).

A $I T \& T$ tinha vultosos investimentos no Chile, de serviços de telefonia, à rede de hotéis Sheraton e o jornal El Mercurio. O aumento de popularidade de candidatos como Allende e de um projeto de sociedade como o da UP preocupavam o empresariado. O livro "The Pinochet File", escrito por Peter Kornbluh (2003) logo após a abertura dos arquivos da CIA sobre o envolvimento no Chile, descortina a tentativa da $I T \& T$ de fornecer recursos financeiros a CIA para que fossem empregados em esforços contra Allende. A agência não aceitou o dinheiro, mas indicou o nome de um indivíduo de confiança que poderia canalizar os fundo para campanha de Jorge Alessandri.

Durante o governo Allende, a IT\&T investiu forte na campanha de oposição, procurando articular outras empresas no sentido de exercer pressão econômica contra o Chile. Além do já mencionado Committee on Chile, a IT\&T foi aos bancos fazer lobby em prol do retardamento de créditos ao Chile. Com a chegada Allende ao poder, o Chile teve o crédito de curto prazo cortado por cinco bancos norte-americanos: Chase Manhattan, Chemical, First National City, Manufactures Hanover, Morgan Guaranty (WOODIWISS, 2007).

Contudo, as fragilidades do governo Allende não podem ser somente atribuídas à organização do empresariado nacional e transnacional ou ao apoio do governo norte-americano à oposição. Devemos olhar também para o impacto da falta de habilidade do governo em negociar e dialogar 
com sua própria base. Mais uma vez, Aggio e Garretón nos ajudam a ver outras dimensões da crise e das tensões e conflitos internos da esquerda. Outubro de 1972 é também o mês da paralisação caminhoneiros. A reação do governo foi violenta e autoritária, decretando estado de emergência em 10 províncias, o que levou a explosão de revoltas, muitas vezes violentas, em todo o país.

Identificar a paralisação do país com os interesses gerais dos setores empresariais e de classe média contra a política econômica foi decisivo para a direita no sentido desta poder atrair as bases e a cúpula da DC [Democracia Cristã]. Na visão da direita a adesão da DC poderia também dar ao movimento um caráter de oposição popular, isolando ainda mais o governo (AGGIO, 1993, p. 138).

As divergências tornaram-se ainda mais explícitas quando da formação do "polo revolucionário". A crise de outubro catapultou o nascimento de novas organizações populares, notadamente os Cordões Industriais e os Comandos Comunais, que apostavam na radicalização e no aprofundamento das reformas, em oposição à política de negociação mais ampla defendida pela UP. Observa-se ainda, uma fratura no interior da MAPU, derivada de contendas entre os grupos políticos em seu interior. Nas disputas, destaca-se um segmento claramente atraído pelas propostas do "polo revolucionário" e o MAPU-Obrero/ Campesino (MAPU-OC), alinhado com os comunistas. Esses embates e antagonismos comprometeram a base de apoio popular da UP, contribuindo para a crise de legitimidade do governo (AGGIO, 1993, p. 145-152).

\section{O papel dos EUA na ditadura empresarial-militar chilena}

O golpe militar que derrubou o governo de Salvador Allende aliviou as tensões ente EUA e Chile. A CIA suspendeu as operações clandestinas, mas continuou a financiar projetos de propaganda política. O tom dos discursos, contudo, tornou-se celebratório, contribuindo com os canais de mídia aliados a criar uma imagem positiva da Junta militar no poder.

No tocante à truculência do regime e às acusações de tortura e a violação de direitos humanos, observou-se o envolvimento indireto da CIA. Desde 1974, a CIA designou uma equipe responsável pela coleta clandestina de informações sobre tortura e outros tipo de violação de direitos humanos no Chile como desaparecimento, sequestros e execuções. 
Os relatórios da CIA informam que a agência sabia e informava constantemente o governo norte-americano sobre tais práticas no Chile (CIA Activities in Chile, 2000). A agência também estava a par também e contribuiu para a "Operação Condor", projeto cooperativo de inteligência, articulado pelos governos do Brasil, Argentina e Chile, para rastrear e neutralizar a oposição no Cone Sul. Documentos recentes liberados pelo Departamento de Estado norte-americano através da publicização de telegramas trocados entre o embaixador norte-americano no Paraguai Robert White e o Secretário de Estado Cyrus Vance atestam tal articulação e envolvimento. Em conversa com o chefe das forças armadas paraguaias, general Alejandro Fretes Davalos, este revela ao embaixador que os encarregados da inteligência sul-americana "mantém contato por uma central de comunicações norte-americana instalada na zona do canal do Panamá, que cobre toda a América Latina". Tal infraestrutura é usada para "coordenar informações da inteligência entre os países do Cone Sul" (Second Meeting with Chief of Satff re Leitelier Case, 1978).

As violações de direitos humanos também eram conhecidas e formalmente condenadas, consideradas prejudiciais à reputação internacional e, portanto, inaceitáveis para os EUA (CIA Activities in Chile, 2000). Os informantes chilenos, contudo, eram indivíduos notórios pelo envolvimento nesse tipo de abuso, a exemplo do chefe da polícia secreta chilena, Manuel Contreras Sepulveda, acusado do assassinato do embaixador chileno Orlando Letelier. Além disso, um memorando enviado ao presidente de assuntos internacionais, o tenente Brent Scowcroft, traz fortes indícios de tentativas do governo norteamericano em aliviar a pressão internacional sobre o governo Pinochet, particularmente da ONU, no tocante às sanções relativas à violação de direitos humanos (Memorandum for Lieutenant General Brent Scowcroft, Subject: Chile, 25 de Julho 1975).

Mais comprometedor talvez tenha sido o envolvimento da CIA na criação da DINA, polícia secreta chilena. Segundo Kornbluh, a CIA teria enviado uma equipe para ajudar na fundação e estruturação da DINA. $\mathrm{O}$ auxílio implicava em suporte infraestrutural, recursos humanos e treinamentos em como conduzir operações de inteligência. $\mathrm{O}$ manual da DINA sobre como conduzir operações de inteligência consiste numa cópia traduzida de um velho manual norte-americano dos anos 1950. $\mathrm{O}$ autor comenta, contudo, que ao longo de suas pesquisas no Chile e nos EUA encontrou poucos documentos detalhados sobre as relações entre a CIA e a DINA, a maioria dos arquivos e registros simplesmente desapareceram (KORNBLUH, 2003). 
Para as corporações transnacionais, a política econômica adotada pelo governo militar trouxe inúmeras vantagens. A ditadura no Chile destacou-se no contexto dos regimes militares do Cone Sul por adotar uma política econômica monetarista, em contraste com os projetos desenvolvimentistas vigentes no Brasil, Argentina e Peru. O Chile, o primeiro país a implementar pacote neoliberal de ajuste estrutural em meio a uma ordem política ditatorial, era descrito por alguns intelectuais como o livre mercado do terror (WOODIWISS, 2007, p. 176).

Os primeiros contatos com as ideias neoliberais se deram ainda nos anos 1950, no contexto de modernização e implementação de reformas sociais, por meio de intercâmbios acadêmicos promovidos por professores da Universidade Católica do Chile em 1953. A tentativa dos professores Alfredo Silva, Julio Chaná e do engenheiro comercial Patricio Ugarte em estabelecer um instituto de pesquisa dentro dessa linha não surtiu muito efeito, sendo a proposta veementemente rechaçada. Em 1955, o Projeto Chile, levado a cabo pela Universidade do Chile teve maior sucesso, firmando um contrato de cooperação acadêmica e intercâmbio de pesquisa entre as Universidades de Chicago e do Chile pelo período de 1956 a 1964 (FISCHER, 2009, p. 305-347). Dos anos 1950 datam também as primeiras iniciativas de se construir uma rede transnacional de contatos entre o empresariado e os intelectuais de Chicago. Lideranças e representantes de grandes conglomerados chilenos, como Manuel Cruzat, foram treinados em Chicago. A SOFOFA promoveu diversos cursos de forma difundir o ideal neoliberal entre o empresariado local. Mais tarde, esses mesmos homens teriam um papel protagonista na desarticulação da UP e no governo da Junta, exercendo funções ministeriais e consultivas (O'BRIAN; RODDICK, 1983. CAMPERO, 1984. SILVA, 1996).

Como podemos perceber, a história e a trajetória das ideias neoliberais no Chile não surgiram ou foram importadas às pressas por conta da crise econômica e política vivenciada pelo Chile na década de 1970. Uma importante parte da base social e política do neoliberalismo chileno emergiu justamente dessas universidades, especialmente a Católica, morada do movimento gremialista (FISCHER, 2009, p. 305-347). $\mathrm{O}$ gremialismo consistia em um movimento de base que congregava estudantes e professores conservadores, parte dos setores médios e o pequeno empresariado na defesa da sociedade contra as "garras do marxismo".

O triunfo do neoliberalismo como sistema social foi, assim, fruto de um processo socialmente construído, em meio a conflitos com 
outros projetos alternativos em concurso. Conforme explica Verónica Valdivia Zárate, diversas questões não estavam tão claras e definidas nos primeiros anos após o golpe.

Conviviam no interior das forças armadas pelo menos dois grandes grupos, um setor profundamente anticomunista, para o qual a tese do inimigo interno, expressa pela Doutrina de Segurança Nacional, tinha forte apelo; e outro que enfatizava a necessidade de reformas sociais e econômicas de caráter estrutural. Como podemos perceber, ambos tinham em mente neutralizar o marxismo e por fim definitivamente a UP; as saídas propostas eram, todavia, diferentes, o primeiro apostando na repressão aliada a uma política de crescimento alicerçada na abertura irrestrita da economia ao mercado internacional e o segundo no desenvolvimento assentado em políticas de caráter nacionalista.

Essa falta de unidade é o que explica que nos anos seguintes ao golpe as forças armadas foram receptivas a distintos discursos políticos, encontrando eco na maioria dos grupos que haviam pressionado pela intervenção. Nesse aspecto, houve setores militares receptivos ao discurso nacionalista, outros ao neoliberal, ao nacional desenvolvimentismo, ao corporativista... (ZARATE, 2001, p. 2)

Segundo a historiadora chilena, à época da derrubada do governo Allende, havia um plano de ação, a luta contra a UP contribuiu para unificar os setores militares em disputa, mas não um projeto global de organização da sociedade. O processo de superação do neoliberalismo frente a outros projetos de cunho desenvolvimentista ou corporativista, se deu pari passu ao processo de preponderância do exército sobre as outras forças e do general Pinochet sobre outros comandantes.

Essa visão dos acontecimentos contrasta com teses mais tradicionais ancoradas nos estudos de Samuel Huntington que, com o tempo, formaram um forte consenso em torno da hipótese segundo a qual o caráter profissional das forças armadas chilenas e a verticalidade de poder de mando foram, em grande medida, o que permitiu o general Pinochet a impor o neoliberalismo. Após o golpe, os oficiais teriam retornado aos quartéis para desempenhar tarefas profissionais habituais, afastando-se da política, a qual teria sido construída por grupos civis com a aprovação dos militares. (HUNTINGTON, 1996; ARRIAGADA, 1985; VALENZUELA, 1993).

Zárate sustenta que o modelo neoliberal rompia com a trajetória do pensamento militar em relação à dupla Estado-desenvolvimento e, por 
isso, a oposição militar ao papel condutor, intervencionista do Estado, representada pelo comandante chefe da força aérea Gustavo Leigh, foi significativa.

$\mathrm{Na}$ disputa saíram vitoriosos civis e militares alinhados com o neoliberalismo. A configuração e consecução das reformas surgiram do trabalho conjunto entre setores da sociedade civil e dos militares. A contribuição civil na construção de uma política econômica regulada pelo mercado, conhecida como El Ladrillo, ficou a cargo dos Chicago Boys, um grupo de economistas formados pela Universidade de Chicago, bastião no pensamento neoliberal e monetarista nos EUA (VALDÉS, 1995).

As medidas incluíam equilíbrio orçamentário e redução dos gastos públicos; controle da inflação através do estímulo ao crédito e investimento privado; desregulamentação dos fluxos financeiros, bem como da indústria e das relações de trabalho; retirada das barreiras alfandegárias e de entraves ao investimento estrangeiro; privatização de empresas e serviços públicos, como parques, prisões, escolas, saúde e pensões.

A adoção das reformas neoliberais no Chile foi celebrada pelo FMI, Banco Mundial, pelo empresariado transnacional e pela grande mídia como a saída para o crescimento e desenvolvimento a ser implementada por outros países na América Latina.

O conjunto de corporações transnacionais anteriormente mencionado, ligado à mineração, telecomunicações, bancos de investimento, lucrou enormemente durante a ditadura do Chile. Mais que isso, juntamente com suas parceiras chilenas, essas empresas foram bem sucedidas na orientação da modernização-conservadora, transnacionalizando precocemente a economia chilena e abrindo ao mundo as portas para o neoliberalismo, seus códigos econômicos, políticos e culturais. Um trabalho que, como vimos no início do texto, vinha sendo desenvolvido com afinco desde os anos 1960, com a participação em organismos privados como o Business Group for Latin America, através dos quais procuravam costurar relações com o governo, influenciar a política externa conforme seus interesses e congregar aliados nos países de investimento.

O regime militar chileno e sua política econômica tinham respaldo de uma parcela significativa da sociedade, que incluía boa parte do empresariado, os setores médios e, inclusive, parte dos setores populares. Essa realidade espinhosa, para a qual muitas vezes tendemos a fechar os olhos, não pode ser ignorada. Acreditamos ser fundamental e urgente 
tocar nessa ferida e discutir a questão do consentimento a regimes truculentos e autoritários.

Levados por essa mesma preocupação e inspirados por um conjunto de estudos europeus, que questionavam o silêncio sobre o colaboracionismo francês em Vichy e sobre o apoio da sociedade civil alemã ao nazismo (BÉDARIDA, 1986; LABORIE, 2010; BROZSAT, 1981; MOMMSEN, 1979), alguns intelectuais brasileiros começaram a se debruçar sobre a problemática do consenso em regimes autoritários.

Daniel Aarão Reis foi um dos primeiros a problematizar a memória sobre a ditadura brasileira. $\mathrm{O}$ autor destaca especialmente a tendência da sociedade em se distanciar da ditadura, evitando, de todas as formas, qualquer associação com o regime. Como aponta Aarão Reis, fica a impressão de que ninguém participara ou consentira com a ditadura; que o regime não tinha base de apoio ou qualquer legitimidade. A ditadura parecia um processo externo à própria sociedade brasileira (REIS, 2005).

Quase ninguém quer se identificar com a ditadura militar no Brasil nos dias de hoje. Contem-se nos dedos aqueles que se dispõem a defender as opções que levaram à sua instauração e consolidação. Até mesmo personalidades que se projetaram à sua sombra, e que devem a ela a sorte, o poder e a riqueza que possuem, não estão dispostas, salvo exceções, a acorrer em sua defesa (REIS, 2005, p. 7-8).

A problemática ressaltada por Reis consiste em entender como um regime supostamente rechaçado pela maioria se manteve por tantos anos; como compreender a permanência no contexto democrático de lideranças e mecanismos de poder construídos e/ou preservados pela ditadura. A hipótese defendida por ele é que se formara um amplo consenso social em torno das propostas e métodos da ditadura, o que garantiu a sustentação do regime. Um conceito de consenso atravessado por matizes, que vão do ativismo militante ao conformismo derrotista e desesperançado 8 ; um conceito ancorado na ideia de "zona cinzenta", proposta inicialmente por Primo Levi e usada por Pierre Labourie para investigar as diversas dimensões de colaboracionismo e resistência

\footnotetext{
8 "O conceito de consenso, na acepção com que emprego, designa a formação de um acordo de aceitação do regime existente pela sociedade, explícito ou implícito., compreendendo o apoio ativo, a simpatia acolhedora, a neutralidade benévola, a indiferença ou, no limite, a sensação de absoluta impotência. São matizes bem diferenciados (...), mas concorrem todos, em dado momento, para a sustentação de um regime político (...). A repressão e, em particular a ação da polícia política podem induzir ao consenso, ou fortalecê-lo, mas nunca devem ser compreendidas como decisivas para sua formação." (REIS, 2010, p. 182).
} 
em Vichy. ${ }^{9}$ A base solidificadora desse consenso, por sua vez, estaria numa cultura política autoritária, da qual a ditadura seria mais um capítulo de uma história marcada pelo autoritarismo (REIS, 2005, p. 9).

Seguindo uma linha bastante similar, Samantha Quadrat vem há alguns anos desenvolvendo uma série de pesquisas sobre o processo de construção da ditadura chilena e sobre a memória do pinochetismo. A autora se dedica a fazer uma revisão das análises influenciadas pela teoria da dependência e pelo marxismo, que, segundo ela, "têm sido pensadas a partir de um modelo comum baseado na doutrina de segurança nacional, criada a divulgada pelos Estados Unidos, país visto em alguns trabalhos, como o grande responsável pelos golpes e manutenção dos governos autoritários deles oriundos" (QUADRAT, 2011, p. 244). Nesse sentido, sua proposta é fazer uma crítica ao tom externalista, procurando entender a ditadura como um processo que responde a questões internas, próprias da sociedade chilena, algo que já vinha sendo feito também por autores marxistas como Aggio e Garretón desde os anos 1980.

Mais do que somente uma crítica ao externalismo, Quadrat apresenta uma proposta para entendimento do processo, apoiando-se na hipótese do amplo consenso, defendida por Reis. $\mathrm{Na}$ apresentação da coletânea organizada junto com Denise Rollemberg, as autoras reafirmam o compromisso de verificar "como os consensos foram criados; como as acomodações de interesses fizeram-se em regimes autoritários através de mecanismos traduzidos em ganhos materiais e/ou simbólicos para as sociedades" (ROLLEMBERG; QUADRAT, 2010, p. 15).

Em suas análises sobre a ditadura chilena, Quadrat afirma que os alicerces do consenso devem ser buscados no medo do comunismo e do possível avanço da esquerda. Para além daqueles que militavam ativamente contra o governo Allende e combatiam conscientemente o marxismo, existia uma sensação de insegurança, fragilidade e medo que estaria difundida por toda a sociedade, atravessando barreiras de classe, nível intelectual, grupo etário, etc. Um medo tão intenso e generalizado que mesmo práticas abomináveis como tortura, sequestro, fuzilamentos e demais violações de direitos humanos tornavam-se aceitáveis, um mal necessário, aos olhos da sociedade. Diante desse cenário, Pinochet, surgia

\footnotetext{
${ }^{9}$ Há de se ter cuidado com certas aproximações. O fascismo é um movimento de massa, envolvente e sedutor politicamente. É uma construção social marcada pela política do espetáculo, apostando no convencimento não apenas através do caráter salvacionista de suas propostas em momentos de profunda fragilidade social ou no reforço a preconceitos e ódios sociais existentes, mas também através do fascínio. A forma sedutora do fazer político, o espetáculo e a empolgação de massas, é algo peculiar ao fascismo. Esse aspecto não é observado nas ditaduras militares. (ARENDT, 1989; GUERIN, 1973; KERSHAW, 1993; MOMMSEN, 1979; PAXTON, 2007; REICH, 1974).
} 
como um líder visionário, salvador e libertador do Chile, expressando a defesa dos valores ocidentais e cristãos, ameaçados durante o governo de Allende por suas influências socialistas (QUADRAT, 2009).

Pinochet temente a Deus, um escolhido de Deus; um homem com uma missão: salvar o Chile; um soldado pronto para defender o país; um pai autoritário, porém acolhedor; com o passar do tempo, um avô; um homem moderno que abraça novas ideias econômicas como o neoliberalismo; que modernizou o Chile e que foi o único a derrotar o comunismo no mundo, o primeiro a martelar o mundo de Berlin (QUADRAT, 2009, p. 405-406).

Como podemos perceber, assim como em Reis, a explicação de Quadrat para sustentação, permanência e força do regime deve ser buscada na anuência e no consentimento da sociedade, ainda que não descartem o papel da repressão. Uma interpretação diametralmente diferente da defendida neste texto, que, sem descartar o papel do apoio popular difuso, entende o processo como resultado de uma articulação de classe - representada nacional e transnacionalmente - aliada ao impacto social, psico-mental (medo) e político dos mecanismos de repressão e alienação.

Nota-se também a tendência em falar da sociedade de forma difusa, como uma entidade amorfa, sem diferenciações, estratos ou classes. Melhor dizendo, esses espaços sociais particulares, os diferentes lugares de fala não são exatamente negados, mas, na visão desses autores, essas experiências sociais diferenciadas e desiguais não representam nenhuma influência na construção da opinião dos indivíduos. Assim, a problemática é constantemente apresentada em termos generalizantes do tipo "a sociedade consente", "a sociedade legitima". Os grupos e manifestações da oposição aparecem como marginais, expressões fora da ordem, destacados ou externos à sociedade.

As pesquisas de Quadrat mostram efetivamente que o apoio a Pinochet podia ser encontrado nas mais variadas esquinas, nos mais variados trajes. Ao redor dele, em apoio a suas ideias e propostas, mesmo após a sua morte, reuniram-se milhares de chilenos; não apenas empresários e setores médios, mas também donas de casa, eletricistas e parte da juventude atual. De sua prisão em Londres, passando pelo regresso ao Chile no ano 2000, até o momento de seu enterro, observou-se as mais variadas manifestações de solidariedade, carinho a apoio, demonstrando que "o pinochetismo atrai diferentes gerações de chilenos em todas as classes sociais. Homens e mulheres, adultos e jovens" (QUADRAT, 2009, p. 414). 
O que procuramos ponderar, primeiramente, é até que ponto os discursos de indivíduos isolados são representativos da "sociedade" como um todo? Não fariam os resistentes também parte da sociedade? Da mesma forma que encontramos demonstrações de pinochetismo, encontramos também expressões de crítica e rechaço, vozes estas que não encontravam espaço em um ambiente de repressão, violência e medo. Além disso é preciso analisar com cuidado o impacto da despolitização experimentada por boa parte da população chilena a partir do golpe. Patricio Silva fala de um processo constante de desativação política em prol da marketização da sociedade chilena e da sedução exercida pela lógica do consumismo sobre aqueles que ainda detinham algum poder de consumo.

Conforme a lógica do mercado penetrava os caminhos da política no país, a mídia e particularmente a televisão se tornou a principal arena na qual 'novos políticos' 'vendem' seus 'produtos' eleitorais a uma massa despolitizada que espera soluções rápidas e concretas para seus problemas e demandas particulares (SILVA, 2006, p. 40).

Nesse sentido, será que realmente podemos falar de consenso em um sentido tão amplo? Não pegar em armas por medo é consentir? Não poderiam existir formas de resistência passiva? Um consenso forjado a partir do fogo e da alienação pode ainda ser chamado de consenso? E, finalmente, até que ponto, Pinochet e as políticas implementadas pela ditadura efetivamente representavam os interesses desses setores todos?

Em um artigo de 1989, Garretón faz um panorama das mobilizações e protestos ocorridos durante a ditadura chilena. Segundo o sociólogo, essas manifestações nunca cessaram, mesmo diante de forte repressão do Estado. Entre 1973 e 1983, são observadas mobilizações recorrentes, todavia setoriais, localizadas e de curta duração. Eram organizadas por estudantes, grupos da periferia (poblaciones), organizações operárias e camponesas, Igreja e grupos em defesa dos direitos humanos, trazendo pautas particulares como: melhora das condições de vida nas poblaciones, reivindicações trabalhistas, defesa de direitos humanos, intervenções culturais, etc. A partir de 1983, Garretón aponta um aprofundamento das mobilizações sociais no ciclo de protestos nacionais e na greve geral de 1986. Nesse segundo momento, há uma articulação nacional dos protestos, deixando explícita a crescente insatisfação por parte de variados setores da sociedade, incluindo os setores médios, base de apoio para o golpe de 1973 e sustentação do regime até o início dos anos 1980. O ciclo de protestos nacionais, iniciado em 11 de maio de 1983, 
tinha uma pauta comum, oposição ao regime, e se expressou de diversas formas como: paralisações parciais, absenteísmo, "operação tartaruga", passeatas, ocupações, "buzinaços" e "panelaços", boicotes e barricadas. A repressão foi intensa e especialmente violenta nas áreas periféricas, sendo declarado Estado de sítio em 1984. Ainda assim, já em 1985 há uma tentativa de se reorganizar os protestos nacionais e a articulação de uma greve geral, puxada em julho de 1986 (GARRÉTON, 1989).

Outro elemento que poderíamos destacar para dimensionarmos melhor o nível de consenso é a necessidade de tamanho investimento em aparelhos de investigação e repressão. Se havia um consenso tão sólido e amplo como supõem os autores, se os "inimigos da nação" eram assim tão poucos e pobremente articulados, para quê destinar tanto tempo, recursos humanos, logísticos e financeiros na construção de uma estrutura repressiva do porte da que tivemos no Cone Sul?

Se a maioria não reagiu, não se organizou em um movimento de oposição em massa, como apontam as pesquisas de Quadrat, cabe-nos indagar sobre o impacto da repressão e da violência política na desestabilização dessas iniciativas, incutindo o medo na sociedade e desencorajando os cidadãos a manifestarem abertamente suas opiniões. Sentir-se acuado, paralisado pelo medo não é consentir. Uma sociedade atravessada pelo medo e pelo terror não é uma sociedade em conformidade com o regime.

Como isso, não estamos a defender que não houve margem de consenso, apenas coloco algumas ponderações para que possamos dimensionar o nível de consenso, não esquecendo a relevância de outros elementos como coerção, violência e autoritarismo nessa equação. Um consenso construído com base no medo de alguns tantos do comunismo, por certo, mas também forjado com o auxílio propagandístico e midiático da CIA e do capital norte-americano e mantido com base no terror e na repressão àqueles que ousavam discordar. Silêncios não designam necessariamente anuência. O que se têm é uma "paz sem voz", alcançada em boa medida pelo terror e pelo medo.

Por mais que possamos identificar discursos de defesa e apoio ao regime em variados setores da sociedade, é preciso ir além dos discursos dos agentes da época e analisar até que ponto o regime realmente representava os interesses de todos esses grupos. Quem ganhou com a ditadura? Essa é uma outra questão espinhosa, para a qual também muitas vezes não queremos olhar, mas da qual também não podemos nos esquivar. Os grupos sociais não foram equivalentemente recompensados, não se beneficiaram na mesma proporção. 
O "milagre do Chile" conseguiu controlar a inflação e aumentar a lucratividade das empresas ligadas ao setor primário-exportador. Petras e Vieux (1990) observam um dinamismo notável nas indústrias de mineração de cobre, pesca, madeireiras e na cultura de uvas e maçãs. Ressaltam ainda a forte parceria com empresas estrangeiras: na pesca, a proeminência de um consórcio Chileno e Neozelandês; na indústria frutífera destacam-se os norte-americanos; na mineração a CODELCO divide espaço com poderosos holdings norte-americanos, suíços e australianos (PETRAS; VIEUX, 1990, p. 59).

Por outro lado, o regime trouxe em seu bojo desemprego em massa, informalização da economia, aumento significativo da pobreza e queda geral da qualidade de vida da imensa maioria dos chilenos. Tironi e Martinez apresentam dados sobre a queda de assalariados na população ativa (54\% em 1971 para 38\% em 1982), o aumento de trabalhadores informais, subempregados e desempregados $(14 \% \mathrm{em}$ 1971 para 36\% em 1982) e jovens excluídos (80\% em 1971 para 49\% em 1982) (TIRONI; MARTINEZ, 1985). Quem realmente lucrou com a ditadura foi o empresariado, em especial os setores ligados ao mercado financeiro, ao comércio internacional primário-exportador e, claro, o setor produtivo transnacional. Eles, mais que qualquer outro, lucraram financeiramente e também politicamente com o golpe e com o regime.

Como podemos perceber, o empresariado é um ator que toma partido, se organiza e luta na arena política em prol da consolidação de seus interesses. E a política faz parte do negócio. Assim como a propaganda é a alma do negócio; a política é a sua arma. Uma arma potente e mortal, contudo transparente, sofisticada, uma arma soft, bem aceita socialmente porque dentro da lei e politicamente correta, mas não menos feroz e violenta.

\section{Referências}

AGGIO, Alberto. Democracia e Socialismo: a experiência chilena. São Paulo: Unesp, 1993.

ARENDT, Hannah. Origens do totalitarismo: anti-semitismo, imperialismo, totalitarismo. São Paulo: Cia das letras, 1989.

ARRIAGADA, Genaro. La politica militar de Pinochet. Santiago: Salesianos, 1985.

BÉDARIDA, François. L'histoire de la résistance: lectures d'hiers, chantier de demain. Vingtième Siècle, n. 11, p. 75-90, juillet-septembre, 1986.

BROZSAT, Martin. The Hitler State: the foundation and development of the internal structure of the Third Reich. London: Longman, 1981. 
CAMPERO, Guillermo. Los gremios empresariales en el periodo 1970-1983: comportamiento sociopolítico y orientaciones ideológicas. Santiago: El Grafico, 1984.

DOMHOFF, G .William. The higher circles. New York: Random House, 1971.

DREIFUSS, R. A internacional capitalista: estratégias e táticas do empresariado transnacional 1918-1986. Rio de Janeiro: Espaço e tempo, 1986.

FISHER, Karin. The influence of neoliberals in Chile before, during and after Pinochet. In: MIROWSKI, Philip; PLEHWE, Dieter (Org.). The road to Mont Pelerin: the making of the neoliberal thought collective. Boston: Harvard Univ Press, 2009. 305-346.

FONTANA, Josep. História, análise do passado e projeto social. Bauru: Edusc, 1998.

GARRETON, Manuel A. Mobilizações populares, regime militar e transição para democracia no Chile. Lua Nova: Revista de Cultura e política, São Paulo, n. 16, p. 87-102, mar. 1989.

GARRETON, Manuel A.; MOULIAN, Tomás. La Unidade Popular y el conflicto politico en Chile. Santiago: LOM Ediciones, 1983.

GUERIN, Daniel. Fascismo y Gran Capital. Madrid: Editorial Fundamentos, 1973.

GRAMSCI, Antonio. Cadernos do Cárcere. Rio de Janeiro: Civilização Brasileira, 2002. Vol. 3.

HUNTINGTON, Samuel. O soldado e o Estado: teoria e política das relações entre civis e militares. Rio de Janeiro: Bibliex, 1996.

KERSHAW, Ian. Hitler: um perfil do poder. Rio de Janeiro: Zahar, 1993.

KLEIN, Naomi. The Shock Doctrine: the rise of disaster capitalism. New York: Picador, 2008.

KORNBLUH, Peter. The Pinochet File: a declassified dossier on atrocity and accountability. New York: The New Press, 2003.

LABORIE, Pierre. Os franceses do pensar-duplo. In: ROLLEMBERG, D.; QUADRAT, S. (Orgs.). A construção social dos regimes autoritários. Rio de Janeiro: Civilização Brasileira, 2010. Vol. 1. p. 31-44.

MOMMSEN, Hans. National Socialism: continuity and change. In: LAQUEUR, W. Fascism: a reader's guide. New York: Penguin Books, 1979.

O'CONNOR, James. USA: a crise do Estado capitalista. Rio de Janeiro: Paz e Terra, 1977.

O'BRIAN, Phil; RODDICK, Jackie. Chile: The Pinochet decade: the rise and fall of the Chicago Boys. London: Latin America Bureau, 1983.

PAXTON, Robert. A anatomia do fascismo. São Paulo: Paz e Terra, 2007.

PETRAS, James; VIEUX, Steve. The Chilean "economic miracle": an empirical critique. Critical Sociology, v. 17, p. 2, Summer 1990.

POULANTZAS, Nicos. O Estado, o poder, o socialismo. Rio de Janeiro: Graal, 1985.

QUADRAT, Samantha. Para Tata, com carinho! In: AZEVEDO, C.; ROLLEMBERG, D.; KNAUSS, P.; BICALHO, M.F.; QUADRAT, S. (Orgs.). Cultura política, memória e historiografia. Rio de Janeiro: FGV, 2009. 399-418.

. Ditadura, violência política e direitos humanos na Argentina, no Brasil e no Chile. In: AZEVEDO, C.; RAMINELLI, R. História das Américas: novas perspectivas. Rio de Janeiro: FGV, 2011. 
REICH, Wilhelm. Psicologia de massas do fascismo. Porto: Escorpião, 1974.

REIS, Daniel Aarão. Ditadura, anistia e reconciliação. Estudos Históricos, Rio de Janeiro, v. 23, n. 45. p. 171-186, jan.-jun. 2010.

. Ditadura militar, esquerdas e sociedade. Rio de Janeiro: Zahar, 2005.

ROLLEMBERG, Denise; QUADRAT, Samantha (Orgs.). A construção social dos regimes autoritários: legitimidade e consenso no século XX. Rio de Janeiro: Civilização Brasileira, 2010. Vol. 1.

SAMPSON, Anthony. The Sovereign State: the secret history of ITT. London: Hodder and Stoughton, 1973.

SCHRIFTGIESSER, Karl. Business comes of age: the story of the Committee for Economic Development and its impact upon the economic policies of the United States 1942-1960. New York: Harper and Brothers, 1960.

SILVA, Patricio. The politics of neo-liberalism in Latin America: legitimacy, depoliticization and technocratic rule in Chile. In: ROBINSON, Richard (Ed.). The Neo-Liberal Revolution. London: Palgrave, 2006. p. 39-57.

SILVA, Eduardo. The State and the Capital in Chile: business elites, techonocrats and market economics. Boulder: Wetsview, 1996.

TIRONI, Eugenio; MARTINEZ, Javier. Las classes sociales en Chile: cambio y estratificación 1970-1980. Santiago: Sur, 1985.

VALDES, Juan Gabriel. Pinochet's economists: the Chicago School of economics in Chile. Cambridge: Cambridge Univ. Press, 1995.

VALENZUELA, Arturo. Los militares en el poder. In: DRAKE, P; JAKSIC, I. El dificil camino a la democracia en Chile. Santiago: Flacso, 1993. p. 57-144.

WOLFE, Alan. America's Impasse: the rise and decline of growth politics. New York: Pantheon, 1981.

WOODIWISS, Michael. Capitalismo Gangster: quem são os verdadeiros agentes do crime organizado. Rio de Janeiro: Ediouro, 2007.

ZÁRATE, Verónica Valdivia. Estatismo y Neoliberalismo: un contraponto militar. Chile 1973-1979. Historia. Vol. 34. Santiago, 2001.

\section{Documentos Eletrônicos:}

CIA Activities in Chile. September 18, 2000. Disponível em: <www.cia.gov/library/ reports/general-reports-1/chile/\#18>. Acesso em: 9 mar. 2014.

Página eletrônica SOFOFA. historia SOFOFA. Disponível em: <http://web.sofofa.cl/ corporativa/quienes-somos/estructura-corporativa/>. Acesso em: maio 2014.

Página eletrônica SOFOFA. Qué es SOFOFA? Disponível em: <http://web.sofofa.cl/ corporativa/quienes-somos/ique-es-sofofa/> . Acesso em: maio 2014.

Memorandum for the Record, Subject: Minutes of the 40 Committee Meeting, 8 Sept 1970, September 9, 1970. Disponível em: <http://nsarchive.gwu.edu/news/20001113/700909. pdf>. Acesso em: maio 2014.

State Department Cable, U.S. Ambassador Robert White (Paraguay) to Secretary of State Cyrus Vance, Subject: Second Meeting with Chief of Satff re Leitelier Case, October 20, 1978, Confidential, 1p. Disponível em: <http://nsarchive.gwu.edu/news/20010306/ condor.pdf>. Acesso em: maio 2014. 
Memorandum for Lieutenant General Brent Scowcroft, Subject: Chile, July 25, 1975. Disponível em: <http://nsarchive.gwu.edu/news/20001113/750725.pdf>. Acesso em: maio 2014.

Recebido: 17 de novembro de 2015 Aprovado: 14 de fevereiro de 2016

\section{Autor/Author:}

TATIANA PoGGI <tatiana.poggi@gmail.com>

- Professora de História Contemporânea da Universidade Federal Fluminense (UFF). Possui mestrado e doutorado em História Social, defendidos na mesma universidade. Pesquisa temas correlatos à História Contemporânea e História do Tempo Presente; História dos EUA e da Europa; Movimentos Conservadores; Fascismo/Neofascismo; Neoliberalismo e Relações Internacionais. Publicou recentemente o livro Faces do Extremo: o neofascismo nos EUA 1970-2010 (Prismas, 2015).

- Professor of Contemporary History at the Universidade Federal Fluminense. She has received Masters and Doctoral degrees in Social History by the Universidade Federal Fluminense. Her research focuses on the fields of Contemporary History; History of the USA and Europe; Conservative Movements; Fascism/Neofascism; Neoliberalism and International Relations. She has recently published Faces do Extremo: o neofascismo nos EUA 1970-2010 (Prismas, 2015). 